\title{
The Importance of Context in Understanding Homelessness and Mental Illness: Lessons Learned From a Research Demonstration Project
}

\author{
Carol T. Mowbray \\ University of Michigan-Ann Arbor \\ Deborah Bybee \\ Michigan State University
}

\begin{abstract}
Research reports on the housing outcomes for persons who are homeless and mentally ill have focused on client characteristics, program type, and services as independent variables, with mixed results. From social work practice, evaluation theory, and public policy perspectives, context is an important variable. Yet, it has received scant research attention in studies of the outcomes of persons who are mentally ill and homeless. This article summarizes research results from a demonstration project providing outreach or linkage services to this target population, illustrating the significant impact of context variables (site and recruitment source) on client characteristics, implementation, qualitative and quantitative service assessments, and housing outcomes. The discussion suggests how these contextual factors may operate, and it goes on to make recommendations to improve social work research and practice concerning the important dimensions of context that should be assessed.
\end{abstract}

Homelessness in America continues to be identified as a critical social problem and one that is still increasing in breadth, depth, and complexity. Persons who are homeless and mentally ill have now been clearly identified as a minority of all homeless persons (approximately one third according to Fischer, Drake, \& Breakey, 1992). However, it is also clear that these individuals constitute a group with a multiplicity of problems - of critical intensity and requiring attention.

Authors' Note: This research was supported, in part, by a grant from the National Institute of Mental Health (No. H87 MR) to the Michigan Department of Mental Health. Correspondence may be addressed to Carol T. Mowbray, University of Michigan, School of Social Work, 1080 South University, Ann Arbor, MI 481009-1106.

Research on Social Work Practice, Vol. 8 No. 2, March 1998 172-199

1998 Sage Publications, Inc. 
A substantial amount of public funding from federal and state sources has been invested in attempted solutions to the problems of homelessness and mental illness. However, the number of descriptive reports in the literature greatly exceeds that for reported evaluations of these programs. Indeed, although general principles for serving persons who are homeless and mentally ill have been articulated (Blankertz \& Cnaan, 1992, 1994; Blankertz, Cnaan, White, Fox, \& Messinger, 1990; Sheridan, Gowen, \& Halpin, 1993; Susser, Goldfinger, \& White, 1990) and agreed on-on the basis of clinical experience, values, or common sense-no one model with documented effectiveness in multisite replications has emerged so far from our public investments.

Difficulties in conducting effectiveness research on services to homeless populations must, of course, be acknowledged. Several writers have summarized these problems: differing definitions of homelessness (i.e., based on length or chronicity) and sampling frames (shelter users, street dwellers, those inadequately housed, inmates of institutions, etc.); noncomparability in methods of assessing mental health and substance abuse status (e.g., clinical judgment versus structured instruments); use of measures not validated on homeless populations; high attrition rates in longitudinal research; difficulties in defining and measuring services; and so on (Cohen, Mowbray, et al., 1993; Dennis, Buckner, Lipton, \& Levine, 1991; Fischer, 1989; Johnson, 1989; Ribisl et al., 1996). These problems are exacerbated concerning persons who are homeless and mentally ill, where there may be more difficulties in obtaining informed consent, sometimes due to suspiciousness; in tracking and locating participants for follow-up; in appropriate and valid instrumentation; and so on.

Although articulation of these research problems and potential solutions is no doubt helpful to research investigators in this field, attention to the conceptual models that underlie our research appears to be as important an issue but one that has received substantially less concerted attention. By a research conceptual model, we mean the model that maps the domains the research is studying and the expected relationships between the independent and dependent variables. So far, outcome research on homelessness and/or mental illness has used a variety of dependent variables reflecting housing and related outcomes. However, the categories of independent variables studied have been limited to client characteristics, program type, and, to a limited extent, service variables. This simple model is depicted in Figure 1.

Client characteristics, as independent variables affecting housing outcomes, have been examined in a number of research reports. Thus, for example, Caton, Wyatt, Grunberg, and Felix (1990) conducted a pre-post 


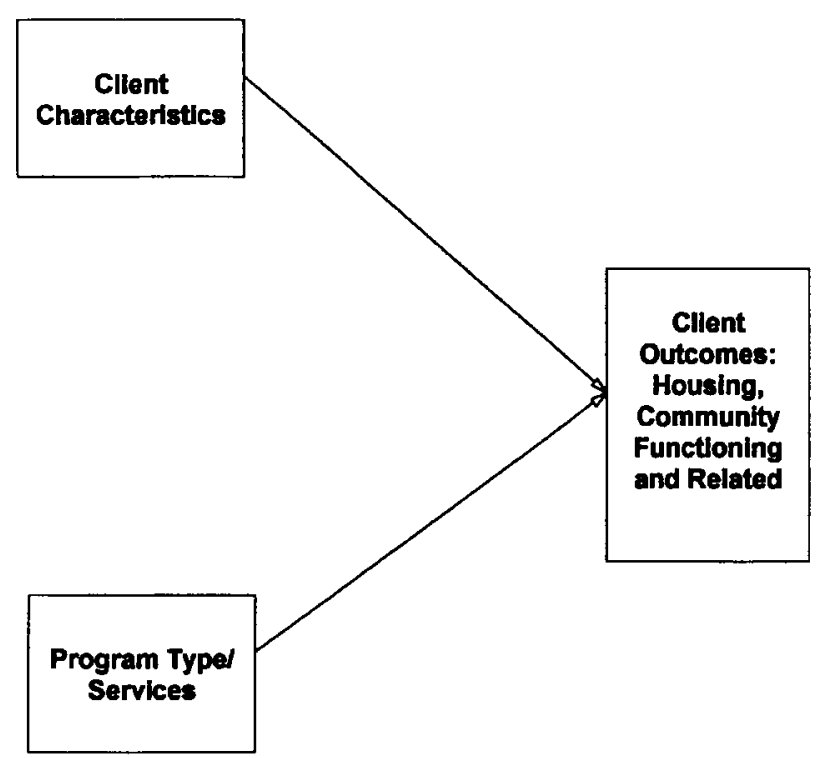

Figure 1: Simple conceptual model of homelessness outcomes.

evaluation of a mental health day treatment program for homeless men. They found that differential rates of homelessness and psychiatric hospitalization related to psychiatric diagnosis, drug abuse, and living independently. Other researchers have examined the relationship of homelessness status and client-level variables such as age, race, gender, income, education, employment, psychiatric symptomatology, substance abuse, and homelessness histories. However, consistent relationships between participant characteristics and outcomes have not been frequently observed (Belcher, 1991; Hagen, 1987; Leda \& Rosenheck, 1992; Toomey, First, Rife, \& Belcher, 1989).

Many reports studying outcomes for individuals who are homeless and mentally ill have examined program type as an independent variable: Lipton, Nutt, and Sabatini (1988) used an experimental design to examine homeless outcomes and psychiatric symptomatology for participants randomly assigned at discharge from a psychiatric emergency service to either a specialized residential program or to the standard aftercare services. Morse, Calsyn, Allen, Tempelhoff, and Smith (1992) examined 12-month differential out- 
comes of homeless participants assigned to either traditional outpatient mental health treatment, a daytime drop-in center, or a continuous treatment team approach. In other studies, program type has included mobile outreach (Cohen \& Marcos, 1992; Marcos, Cohen, Nardacci, \& Brittain, 1990), crisis-oriented psychiatric hospitalization (Bennett, Gudeman, Jenkins, Brown, \& Bennett, 1988), money management services (Stoner, 1989), enhanced programming at homeless shelters (Argeriou \& McCarty, 1993), assertive community treatment (Solomon \& Draine, 1995), vocational training (Hoff, Briar, Knighton, \& Van Ry, 1992), and mobile team-based intensive outreach and case management (First, Rife, \& Kraus, 1990). (For a review of social work interventions, see Johnson \& Cnaan, 1995.) Evaluation results, comparing the various treatment conditions without regard to client characteristics, have been reported-again with mixed results.

A few studies of persons who were homeless and mentally ill have attempted to deconstruct the black box of a program into its service components and/or to quantify amount of services received. In these studies, measures of service or program amounts and types have been examined as independent variables, rather than the simple categorization of whether the individual was assigned to a program. This allows the impact of these variables to be compared with client variables. Thus, Rife, First, Greenlee, Miller, and Feichter (1991) examined, as an outcome, the length of engagement for clients in a mobile case management program. The service variable, number of case manager contacts, was the strongest predictor; but, client characteristics were also significant (functioning, substance abuse, age, prior psychiatric and homeless history). Blankertz and Cnaan (1994) found that program variables (program type and number of positive rewards) contributed significantly to prediction of outcomes among two residential programs, but client characteristics did not. Barrow, Hellman, Lovell, Plapinger, and Streuning $(1989,1991)$ examined the effectiveness of five demonstration projects for homeless mentally ill persons in New York City vis-à-vis obtaining housing and remaining housed. Client descriptors (socioeconomic status, level of functioning) significantly affected these variable outcomes, as did measures of the service process (early initiation of entitlement referrals, provision of housing services, and client disagreement with housing goals). On the other hand, Morse, Calsyn, and Allen (1994) found that service variables (number and types of contacts) affected client outcomes (number of days housed), but client characteristic variables (i.e., race, diagnosis, homeless history) did not. Blankertz, Cnaan, and Saunders (1992) found day program participation to significantly predict rehabilitation outcomes, whereas client demographic characteristics were only marginally related. 
Overall, it might be concluded that examination of these three categories of independent variables in their effects on housing outcomes for individuals who are homeless and mentally ill has produced mixed results. That is, some client characteristic variables in some studies have affected outcomes; similarly, some types of programs or some aspects of service process have demonstrated significant effects. However, these results have been far from consistent. Of course, given our understanding of the variability in providing services and of the problems in measuring client characteristics and functioning, this might come as no surprise. It might be, though, that the omission of other factors in our research conceptual models is affecting our ability to see meaning in our results. One important factor that is seldom considered in these housing outcome studies is that of context.

Contextual factors-representing the physical, social, or emotional environment-are of major importance in social work practice with any population. This includes the influence of the family, the neighborhood, the community, and the culture. These contextual factors are an important component to understanding outcomes according to an ecosystems perspective. In the evaluation literature, the conceptual model advocated by Chen (1990) and others, using program theory, has identified the need to examine micro and macro context variables impacting outcomes, along with characteristics of clients, implementors, and delivery mode. Micro context refers to the fiscal or program environment that houses the services. Macro context refers to the societal or community environment in which the services are delivered, reflecting, for example, stigma and discrimination toward particular groups. Contextual factors have also been recognized as significant in the policy literature concerning housing and homelessness. For example, Bachrach (1992) has commented that characteristics of homeless persons may differ by geographical area. In describing sheltered care environments for persons who are mentally ill, Carling (1992) concluded that the characteristics of the community are often more important than those of the individual in predicting participation in community life. Attention to contextual factors in research and services addressing homelessness is particularly important due to the established connection between external factors such as housing availability or affordability and the prevalence of unhoused persons (Kiesler, 1991). Context is also important because of known differences, by location, in resources and policies directed to homeless persons: for example, the number and type of shelters; limitations on shelter admissions or length of stay; local ordinances criminalizing foraging; and police procedures around transporting homeless persons to jails, psychiatric settings, and shelters. 
However, although context has been acknowledged as critically important in both social work and evaluation theories, research on the effects of contextual variables has rarely been conducted. In fact, Shadish (1993) points out that although some social science researchers have examined contextual variables such as multiple situations or multiple occasions, these selections were haphazard at best and little thought has been given as to careful and systematic sampling of these options to better establish causal inferences.

Thus, it comes as no surprise that in our literature search of articles concerning housing outcomes for populations that were homeless and/or mentally ill (through psychological abstracts during the period 1984-1994), only two research reports were located that examined any measure of context as potential predictors. In both cases, the one contextual variable studied appeared to be derived idiosyncratically. In the first case, reported by Dixon, Friedman, and Lehman (1993), homeless persons served by an assertive community treatment team had different outcomes depending on whether they were referred "from the hospital or from the street"; client variables also had an impact. Susser, Lin, and Conover (1991) found that for patients entering a state hospital, urban residence (along with client variables) increased the risk of homelessness significantly.

A more complete research conceptual model of predictors of homeless outcomes is presented in Figure 2. As discussed in the policy literature, examples of contextual variables might include housing variables (quality, affordability, availability), resources to prevent or address homelessness, community attitudes toward homelessness and other social problems, transportation access, and economic opportunities. Geographic location may encompass many of these variables. Additionally, context may include interorganizational relationships-the cooperation and service access arrangements with collateral providers, such as substance abuse, health, and entitlements. Thus, in the model, context variables may affect programs and services available to homeless persons, as well as the kinds of homeless persons who do or do not present themselves for service.

The research to be summarized here examined the effectiveness of an outreach or linkage model of providing services to persons who were homeless and mentally ill. In previously published reports, we examined the relationship between various measures of housing outcomes and community functioning and of the three usual categories of independent variables: client characteristics, program type, and amount of services received. However, throughout all of these analyses, we have been impressed with the impact of two contextual variables-service site and recruitment source. As is the case for 


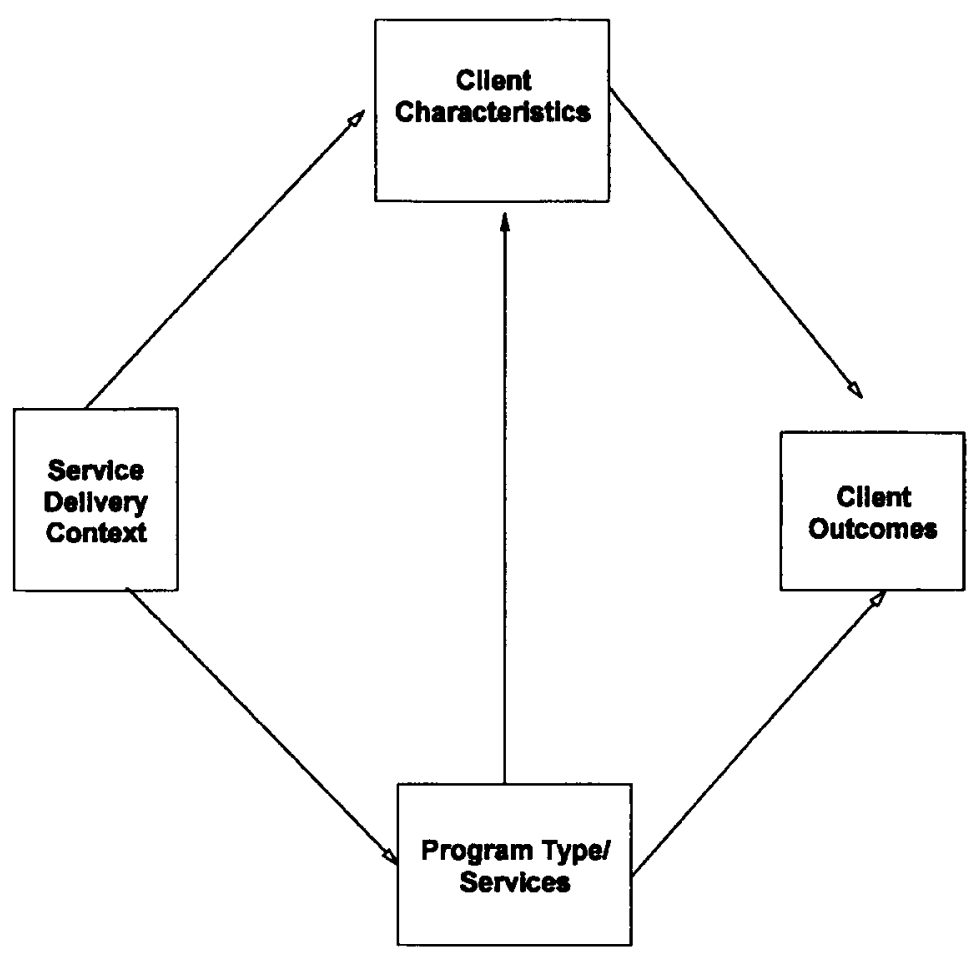

Figure 2: Model of homelessness outcomes incorporating context.

many other researchers, these context variables were initially conceived and analyzed as sources of possible variation that needed to be controlled and minimized. However, despite efforts to do so, they have consistently emerged as major predictors of a variety of results from descriptive, process, and outcome analyses.

In an effort to persuade others of the importance of context and the need for future study, in the remainder of this article we will summarize our results illustrating the significant impact of our context variables. In the discussion, we will then present interpretations of how and why these contextual factors operate. We conclude with suggestions for how context may be better assessed to improve social work research and practice with populations that are homeless and mentally ill. 


\section{METHOD}

\section{Program Description}

The Mental Health Linkage intervention model (Mowbray et al., 1992) was the basis for a research demonstration project, funded by the National Institute of Mental Health and operated in Factorytown and Collegetown. In both sites, a team of mental health workers (4 to 5 FTEs) provided outreach to persons who were mentally ill and either homeless or potentially homeless. Eligible clients were approached by project staff to provide help; complete assessments of functioning, housing preferences, and support needs; and negotiate a plan of housing and services. These contacts and subsequent services were provided by the project staff in a variety of settings that might include the referral site but could also include the street, temporary residence, the homeless project offices, or other places in the community (e.g., prospective apartment sites, Department of Social Services, community mental health $[\mathrm{CMH}]$ agencies). Clients were offered a variety of services in vivo: assistance in obtaining temporary or permanent housing in independent settings (that closely matched the client's needs and preferences); help in establishing income supports, including payee services; training or rehabilitation in daily living and interpersonal or social skills that might increase their ability to live independently; mental health clinical services; and short-term intensive case management. Once clients receiving project services were stabilized in their community functioning, the goal was then to integrate individuals within ongoing service systems. Given their consent, clients were referred from the project to community mental health (nonproject) therapists and/or case managers. Project staff assisted clients in this transition to try and make the referral "stick" and, thus, discontinue clients' homeless project involvement. However, clients could be rereferred to the project or themselves request further services at any time. Staff resources were also used in locating and accessing independent housing sites and working with landlords to maintain housing opportunities. Additionally, at the Factorytown site, the project operated a transitional boarding house (TBH), which was minimally staffed, to provide a temporary independent living setting. Such a residence would also have been desirable in Collegetown but was unaffordable.

\section{Sample}

Eligibility was based on presentation of serious mental illness at screening (diagnosis of psychotic or major mood disorder or severe personality disorder coupled with multiple admissions to inpatient or community acute care 
settings within the last year), county residency, and homelessness (homeless, about to lose housing, or hospitalized with no suitable housing available on discharge). The study participants were relatively young (mean age $=37.5$, $S D=11.0)$, predominantly male $(57.1 \%)$ and White $(58.9 \%)$, with a substantial number $(28.8 \%)$ identified at screening as having substance abuse problems. The focus of the analyses to be reported was individuals accepting some help from the project between October 1, 1989, and December 31, 1990. Implementation analyses also used data collected on clients served in the first screening period, starting on March 1, 1989, before a follow-up research design was put in place.

\section{Contextual Factors}

One of the two contextual factors available for examination was obviously the county site that operated the services (i.e., the county-based community mental health board). Although both counties provided comprehensive, community based services, prioritized to persons with serious mental illness, other factors in their communities provided strong contrasts. Factorytown was characterized by several large manufacturing firms, recent waves of plant closings, and high unemployment rates. Affordable housing was plentiful but often deteriorated or located in high crime or drug use areas. Collegetown, on the other hand, offered more acceptable but less affordable housing, reflecting the impact of two local universities and a proportionately large white-collar or professional population. Of the 163 participants in the followup sample, $60.7 \%$ were from Factorytown and $39.3 \%$ were from Collegetown. Thus, in this research, site encompassed variables reflecting differential resource availability in the two counties. Because each county had a single program, site was also confounded with program level variables such as staffing characteristics, supervisions, and so on.

The other contextual factor studied was recruitment source. By design, the service model and staffing assignments targeted outreach efforts to recruit significant numbers of participants from three sources: homeless shelters, hospitals serving public mental health inpatients, and the existing $\mathrm{CMH}$ caseloads of aftercare clients. Across sites, about equal numbers of the 163 persons in the follow-up sample were recruited from hospital psychiatric inpatient units (36.2\%) and the $\mathrm{CMH}$ caseload (38.7\%), with somewhat fewer recruited from shelters (25.2\%). (Although it should be noted that individuals found at the shelter who were on the $\mathrm{CMH}$ caseload were assigned to the latter recruitment source.) As an independent variable, recruitment source could subsume measured client variables, for example, if individuals using shelters were more likely to be male; it could subsume unmeasured client 
variables, that is, past negative experiences with $\mathrm{CMH}$ affecting current motivation for services; or it could reflect nonclient variables such as services and resources available at a shelter versus a hospital.

\section{Research Design}

The evaluation design examined residential status (where participants were living) at two follow-up time points (4 and 12 months after project entry), as well as residential experiences and use of shelter and mental health services during the 12 months before and after homeless project enrollment. It also compared functioning level characteristics of individuals served at baseline with those same characteristics at the two follow-up time points. Finally, it sought to determine to what extent characteristics of the person or of the intervention (type and amount of services as well as site and recruitment source) related to residential status. Feasibility and costs were considerations in the selection of this longitudinal panel design. We also felt, given our limited knowledge about effective treatment approaches for this population, that the research should serve as a preexperimental search for intervention features and client and setting characteristics related to outcome differences to better identify elements that could be productively included in future experimental designs. Because experimental designs are expensive in terms of time and resources, expending funds for such research on noneffective interventions may be detrimental to long-range research and service goals.

\section{Data Collection}

Data were gathered through five methods: (a) referral forms-providing basic demographic information and residential history for the prior 12 months; (b) ratings-by outreach workers at intake to assess client functioning levels (using the Client Level Assessment Measure; see Hazel, Herman, \& Mowbray, 1991) and at follow-up by trained research assistants obtaining these assessments from a rater most familiar with each client; (c) interviews with participants at 4 and 12 months postenrollment — conducted by research assistants; (d) examination of archival records kept by shelters and psychiatric hospital facilities used by public mental health clients in the two counties, covering the 12-month baseline and 12-month follow-up periods; and (e) management information system data from the two $\mathrm{CMH}$ boards and project records concerning duration and intensity of both homeless project services and mainstream $\mathrm{CMH}$ services during the 12-month baseline and follow-up periods. 
For the 4- and 12-month follow-ups, respectively, 23 (14\%) and $28(17 \%)$ participants could not be located (additionally, 2 were deceased at 4 months and 1 more died before 12 months). An examination of variables related to attrition revealed few significant relationships (see Bybee, Mowbray, \& Cohen, 1994).

\section{Highlights of Program Results}

Previously published studies have described the heterogeneity of the population served (Mowbray, Bybee, \& Cohen, 1993). An implementation analysis conducted on the project indicated that in its fully operational period, it was serving the intended population by site and referral source (Mowbray, Cohen, \& Bybee, 1991). The project achieved a relatively high success rate in engaging clients screened eligible for services, in that $73 \%$ overall accepted some form of project assistance (Mowbray, Cohen, \& Bybee, 1993). This compares favorably to other reports in the literature (Barrow et al., 1989; Rife et al., 1991). The intervention was judged successful in that $87 \%$ of participants were provided with and accepted a permanent-type residence in the community during a 12-month period following initiation of project services, in contrast to their unhoused status at project entry. Furthermore, receipt of project services was found to relate significantly to positive residential outcomes at a 12-month follow-up (Bybee et al., 1994; Bybee, Mowbray, \& Cohen, 1995).

\section{RESULTS}

Results are summarized relating the contextual variables to five sets of analyses from project data: (a) descriptive characteristics of participants, (b) implementation of the service model, (c) quantified service variables, (d) qualitative service assessment, and (e) participant housing outcomes.

\section{Context Related to Descriptive Characteristics of Participants}

A large amount of data was available to describe clients' demographic characteristics, functioning, symptoms, diagnosis, residential histories, and hospital use. To permit a more parsimonious description of the sample, we conducted a cluster analysis to identify groups of individuals whose functioning showed similar levels and patterns (using five relatively independent functioning assessment scales). (Details about measures, scales, and the 
TABLE 1: Homeless Project Clusters by Recruitment Source

\begin{tabular}{lccccc}
\hline & \multicolumn{4}{c}{ Within-Cluster Percentages } \\
\cline { 2 - 5 } & $\begin{array}{l}\text { Hostile or } \\
\text { Psychotic }\end{array}$ & Depressed & $\begin{array}{c}\text { Best } \\
\text { Functioning }\end{array}$ & $\begin{array}{c}\text { Substance } \\
\text { Abusing }\end{array}$ & $\begin{array}{c}\text { Percentage of } \\
\text { Total Sample }\end{array}$ \\
\hline $\begin{array}{l}\text { Homeless total } \\
\text { sample }\end{array}$ & 35.2 & 18.5 & 27.8 & 18.5 & 100.0 \\
$\begin{array}{l}\text { By recruitment } \\
\text { source }\end{array}$ & & & & & \\
$\begin{array}{l}\text { Shelters } \\
\text { Hospitals }\end{array}$ & 26.3 & 0.0 & 26.7 & 0.0 & 16.7 \\
CMH caseload & 34.2 & 35.0 & 16.7 & 35.0 & 29.6 \\
\hline
\end{tabular}

NOTE: $\mathrm{CMH}=$ community mental health. $N=108$; baseline functioning assessments could not be completed for an additional 55 individuals.

a. Cluster distributions differ significantly across referral sources, $\chi^{2}(2, N=108)=15.38$. $p<.05$.

analysis strategy can be found in Mowbray, Bybee, et al., 1993.) Cluster descriptors and membership prevalence are presented below.

Cluster 1-Hostile or Psychotic (35.2\%): highest mean scores on aggression, psychoticism, and community living problems.

Cluster 2-Depressed (18.5\%): highest mean score on depression, low level of substance abuse.

Cluster 3-Best Functioning (27.8\%): fewer than average problems on all scales, relative to others in the sample.

Cluster 4 Substance Abusing (18.5\%): highest mean score on substance abuse, second highest mean score on depression.

The clusters did not differ on demographic or other client characteristic variables, except for diagnosis reflecting colinearity with the cluster-defining scales of depression and psychoticism.

On the context variables, there were significant differences by recruitment source but not by county site. First, as might be expected (see Table 1), members of the Best Functioning cluster were significantly less likely to have been recruited from a psychiatric hospital. Second, individuals recruited from shelters fell in only two categories: Hostile or Psychotic and Best Functioning. Finally, a disproportionately high percentage of both the Depressed and Substance Abusing clusters were recruited from CMH. Thus, in this description of baseline characteristics of clients served by the program, the major nonredundant covariate external to the cluster-defining scales was recruitment source. 


\section{Context Related to Program Implementation}

In the initial phases of service delivery, an implementation evaluation was designed to determine whether the appropriate participants were being served, targeted, and engaged in project services. Each site's outreach team was asked to rate each week every individual seen $(N=270)$ on the extent of their current engagement in project services. In later statistical analyses, the project's research staff assigned a single value to each individual (including those who never accepted project help), representing the highest engagement status given over the course of his or her involvement, as follows:

Full engagement: eligible clients who completed assessments of functioning, housing preferences, and a plan of housing and services, and subsequently accepted project services in the community.

Limited engagement: eligible clients who either accepted some assistance (but never completed assessments or plans) or completed the assessments or plans but never accepted services.

No engagement: clients screened as eligible and contacted but who refused help or disappeared before help could be offered or delivered.

Engagement status was validated through examination of independent daily recordings of staff activities in the computerized management information systems of the operating agencies. (See Mowbray, Cohen et al., 1993 for a full description.) Overall, $73 \%$ of clients achieved full (54.8\%) or limited (18.2\%) engagement statuses.

In our initial implementation analysis, engagement status did not differ by site. However, results from a loglinear analysis suggested engagement differences across recruitment sources that differed by county site (Mowbray, Cohen, et al., 1993). There were no significant differences in rates of engagement by recruitment source at the Collegetown site (see Table 2). For Factorytown, however, the interaction of engagement rate and recruitment source during the implementation period was significant, with marked differences across recruitment sources in the numbers served and in their successful engagement. Thus, we found that during the first screening period from March 1989 through December 1989 (see Table 2), nearly half (46.0\%) of the project's eligible clients were recruited from the $\mathrm{CMH}$ caseload, and they were engaged with remarkable success ( $96.6 \%$ were fully engaged). However, only a small proportion of the total pool of those eligible were recruited from shelters (7.9\%), and only $60 \%$ of those recruited were fully engaged. Although there was a good proportion of those eligible recruited from hospital units ( $46.0 \%$ ), only $24.1 \%$ of these were fully engaged. These results reflected marked deviations from agreed-on project expectations for 
TABLE 2: Engagement Status by Recruitment Source by Site

\begin{tabular}{|c|c|c|c|c|c|c|}
\hline \multirow{4}{*}{$\begin{array}{l}\text { Recruitment } \\
\text { Source }\end{array}$} & \multicolumn{6}{|c|}{ Numbers Eligible (percentages in parentheses) } \\
\hline & \multicolumn{2}{|c|}{$\begin{array}{l}\text { Collegetown } \\
\text { (during all } \\
\text { time periods) }\end{array}$} & \multicolumn{2}{|c|}{$\begin{array}{l}\text { Factorytown } \\
\text { (screening } \\
\text { period } 1^{\mathrm{a}} \text { ) }\end{array}$} & \multicolumn{2}{|c|}{$\begin{array}{c}\text { Factorytown } \\
\text { (screening } \\
\text { period 3) }\end{array}$} \\
\hline & 20 & $(66.7)$ & 5 & $(100.0)$ & 15 & $(66.7)$ \\
\hline & 34 & $(82.4)$ & 29 & $(51.7)$ & 26 & $(61.5)$ \\
\hline CMH caseload & 40 & (72.5) & 29 & $(96.6)$ & 10 & $(90.0)$ \\
\hline
\end{tabular}

NOTE: $\mathrm{CMH}=$ community mental health. Adapted from Mowbray, Cohen, \& Bybee, 1993.

a. Pearson $\chi^{2}(4, N=63)=35.08$.

$p<.0001$.

success in engaging clients by recruitment source-specifically for greater inclusion of individuals from shelters and hospitals. Interventions were initiated at this site, directed toward project staff roles and supervision and their interactions with hospital and shelter personnel-all of which had affected the number and appropriateness of referrals received and thus their motivation to engage in services. Data continued to be collected on engagement status by recruitment source during subsequent time periods. As the right-hand side of Table 2 indicates, by Screening Period 3 (July 1990 through December 1990), the differences were no longer significant. The project staff were able to increase the number of shelter referrals and to achieve higher engagement rates with hospital referrals. However, the number of $\mathrm{CMH}$ referrals dropped.

Thus, the implementation analysis showed that there were initial differences by site in project staff efforts to implement enrollment activities and in the success achieved in fully engaging clients. Although the recruitment sources did differ in characteristics of clients served, it appeared more likely these implementation differences emerged not so much from whether or how project staff differentially engaged clients, but rather in how they interacted with recruitment settings and their staff.

\section{Context and Quantitative Service Analysis}

Following the first screening phase of project services, a system was set up to gather information on types, amounts, and duration of services provided overall to participants, using service activity codes specifically developed for the project's documentation needs. Data on service amounts overall were highly skewed and variable, with nearly $40 \%$ receiving 10 or fewer hours and the remaining $60 \%$ ranging as high as 141 hours of contact. Similar variation 
was seen in terms of the total duration of involvement; the median was 3 months, with $25 \%$ having contact for 6 months or more. In terms of the number of episodes of service (periods of contact separated by a month or more with no project contact), more than $85 \%$ of participants had one or two episodes of service during the 12-month follow-up period.

Information was also collected on the type of each client contact, following service categories defined by the NIMH funding source. To better understand the complex patterns of service receipt, cluster analysis was used to derive groups of clients who had received similar patterns of various service types. Individuals' scores on four variables - number of hours of direct service in housing, case management, mental health intervention, and skill building - were used to define clusters in a hierarchical agglomerative analysis, using average linkage criteria for assignment of cases to clusters. (See Mowbray, Bybee, \& Cohen, 1993, for a complete description of the cluster analysis methodology.) Four clusters resulted. Clients in the Mental Health Focus cluster received, on average, more than four times as many hours of mental health intervention as those in other clusters, coupled with moderate levels of other types of service. Those in the Case Management Focus cluster received nearly four times as much case management service as those in other clusters, in addition to low levels of mental health and moderate levels of housing service. Clients in the Housing Focus cluster received more than twice as much housing service, coupled with low levels of mental health and moderate levels of case management service. The Low Total Service cluster received the lowest levels of mental health, case management, and housing service, in addition to levels of skill development at par with that received by the other clusters. Individuals in this cluster also received significantly fewer total hours of service and were in contact with project staff during fewer total months; they also received less assessment than those in the Mental Health and Case Management clusters. Only 56\% of the individuals in this cluster fully enrolled in project services; the other $44 \%$ declined to participate in assessments and accepted only limited help. Across the other three clusters, $75 \%$ to $80 \%$ were fully enrolled; this difference was significant, $\chi^{2}(3, N=163)=9.00, p<.03$.

To identify covariates of membership in the four service clusters, multinomial logistic regression was used, employing client characteristic and context variables. Project site and recruitment source were significant predictors of cluster membership, although the magnitude of the relationship was small (McFadden's $p^{2}=.15$ ). Compared with those at the Collegetown site, more individuals at the Factorytown site were found in the Case Management and Housing clusters and fewer in the Mental Health cluster. 
Those recruited from shelters or $\mathrm{CMH}$ caseloads (in contrast with those from inpatient psychiatric facilities) were more likely to receive mental health focused intervention. Individuals recruited in shelters were somewhat more likely to receive case management focused interventions and much less likely to receive interventions focused on housing. These effects of recruitment source on service cluster type did not differ by site.

Among those variables not found to covary with service-type cluster were demographics, functioning at intake, diagnosis, and most descriptors of residential history. Only measures of preproject shelter use and preproject CMH service receipt (both of which were highly redundant with recruitment source) showed significant relationships with cluster membership. Although substance abusers received significantly more hours of service than those without substance abuse problems (among those fully enrolled in services), they did not disproportionately constitute any of the four service clusters.

The service analyses showed that service amounts, types, and durations were highly variable, but that individuals could be grouped meaningfully by the patterns of service that they received. Furthermore, context variables of project site and recruitment source were significantly related to these service variables, whereas client characteristics, for the most part, were not. This substantiates practical knowledge of the differences between recruitment sources in the types of services they provided to clients, which were therefore not needed from the project.

\section{Context and Qualitative Process Analyses}

To better understand the clinical aspects of engagement and service delivery for the project, qualitative data were collected through focus group sessions with staff at each site (Mowbray, Thrasher, Cohen, \& Bybee, 1996). Transcripts for each session were coded and frequency data on categories of responses analyzed for distributional differences across county sites. Of particular interest were differences in types of barriers encountered and in strategies used in providing services to overcome these barriers.

The analyses indicated that responses associated with client-level issues predominated at both sites; that is, client barriers and client strategies constituted $56.1 \%$ of total responses. However, nonclient barriers (from other mental health providers, social service, or criminal justice agencies) and strategies to address these barriers were also frequently identified (about $36 \%$ of all responses). Client-level barriers included categories such as clients' disturbing behavior problems $(22.0 \%)$, rejecting behaviors (16.2\%), affects $(12.7 \%)$, substance use $(11.0 \%)$, delusions and hallucinations $(10.4 \%)$, 
TABLE 3: Types of Client Strategies Mentioned by County Site

\begin{tabular}{lcrc}
\hline Client Strategies Categorized & Factorytown & Collegetown & Total \\
\hline Personal relationships & $7(11.1)$ & $20(25.0)$ & $27(18.9)$ \\
Control mechanisms & $16(25.4)$ & $7(8.9)$ & $23(16.1)$ \\
Perks (cigarettes, food, & & & \\
$\quad$ clothes, benefits, etc.) & $9(14.3)$ & $11(13.8)$ & $20(14.0)$ \\
Disconnecting strategies & $10(15.9)$ & $8(10.0)$ & $18(12.6)$ \\
Regular contacts & $6(9.5)$ & $10(12.5)$ & $16(11.2)$ \\
Instructional techniques & $1(1.6)$ & $14(17.5)$ & $15(10.5)$ \\
Rule orientation & $7(11.1)$ & $3(3.8)$ & $10(7.0)$ \\
Other & $7(11.1)$ & $7(8.8)$ & $14(9.8)$ \\
Total & 63 & 80 & 143 \\
\hline
\end{tabular}

NOTE: Table adapted from Mowbray, Thrasher, Cohen, \& Bybee (1996). For county differences, $\chi^{2}(7, N=143)=22.36$.

$p<.01$.

dangerousness $(7.5 \%)$, diagnosis $(7.5 \%)$, and skill deficits $(5.2 \%)$. There were no differences in client barriers mentioned by staff from the two county sites.

However, as can be seen in Table 3, on client-oriented strategies significant site differences were found. Collegetown staff more frequently mentioned strategies of developing personal relationships (establishing trust, showing friendship, etc.) and instructional techniques (such as skill building or joint problem solving). Factorytown staff, on the other hand, more frequently cited control mechanisms (closer monitoring, civil commitment petitions, etc.), rule orientation (establishing rules, drawing boundaries), and disconnecting strategies (asking clients to leave, back off, etc.). These site differences in use of client strategies were particularly interesting given the lack of differences reported for client barriers

We interpreted these results to reflect site differences in staff expertise and skills in dealing with persons who were mentally ill. At the Collegetown site, the administering agency was able to hire full-time workers with mental health experience. However, at the Factorytown site, because of county-based employment policies, only the supervisor position was full time and credentialed. The remaining functions were part-time positions, filled mostly by students and workers with limited experience in human services (Mowbray et al., 1991). Thus, in Collegetown, the strategies were instructional and proactive with an emphasis on empowerment and self-determination. In Factorytown, the strategies were more controlling, coercive and rule oriented. In this qualitative analysis of service delivery, context was also established 
as an important factor. Client characteristics were not perceived to differ by site. However, the external environments for the two programs affected the types of staff employed, and thus appeared to also affect staff's orientation to participants and consequently the kinds of interventions and techniques used.

\section{Context and Outcome Analyses}

Because an experimental design could not be used in the project, outcomes were analyzed vis-à-vis (a) housing and homeless status at 4 and 12 months and (b) service variables as significant predictors of follow-up housing status. From the interview and archival data collected, residences at each time period were characterized as homeless or correctional settings (shelters, street, jail or prison, temporary room), treatment-type settings (formal mental health or substance abuse inpatient, acute care, or residential programs), or permanenttype settings. The latter included independent living (either alone, with relatives, or with nonrelated others) and supervised dependent settings (such as group homes or adult foster care). Results are detailed in Bybee et al. (1994, 1995).

For $80 \%$ of the follow-up cohort $(N=130)$, it was possible to ascertain where they had lived during 9 or more of the 12 postintake months. During this 12 -month period, $82 \%$ of the cohort had some experience with permanent independent housing. (The average person spent more than 6 months of the follow-up year in such settings, although variability among individuals was high.) Forty-five percent spent some time in supervised dependent settings, with an average stay of 2.5 months. Sixty-nine individuals (53\%) spent some time in a homeless or correctional setting during the entire 12-month followup period, with an average total stay of $\mathbf{4 0}$ days. However, for nearly one third, these stays occurred before they obtained their first permanent-type residence. Of the individuals who obtained permanent housing, $51(36 \%)$ were known to have had subsequent episodes of homelessness or incarceration. All but 3 of these had street, shelter, or temporary room stays after their first permanent-type setting; 10 had jail or prison stays. Eighty-four individuals (64\%) spent part of the 12-month follow-up in treatment settings, with an average total stay of 33 days. Of the 142 individuals who obtained permanenttype housing, $66(46 \%)$ subsequently had days in treatment settings (46 in psychiatric hospitals or hospital units, 19 others in acute care residential settings, and 2 in inpatient substance abuse facilities).

Within the limitations of the design, data collected suggest promise for the effectiveness of the Mental Health Linkage model. That is, during the course 
TABLE 4: Multinomial Logistic Regression on Residential Setting at 12-Month Follow-Up $\left(N=132^{a}\right)$

\begin{tabular}{|c|c|c|c|c|}
\hline \multirow[b]{2}{*}{ Predictors } & \multirow[b]{2}{*}{$\begin{array}{l}\text { Global } \\
\text { Wald }\end{array}$} & \multicolumn{3}{|c|}{$\begin{array}{c}\text { Effects on Odds Ratios } \\
\text { (permanent versus temporary) }\end{array}$} \\
\hline & & $\begin{array}{l}\text { Independent } \\
\text { Alone }\end{array}$ & $\begin{array}{l}\text { Independent } \\
\text { With Others }\end{array}$ & $\begin{array}{l}\text { Supervised } \\
\text { Dependent }\end{array}$ \\
\hline Constant & $13.20^{\star *}$ & & & \\
\hline Age group & $10.10^{\star}$ & $2.92^{\star \star}$ & 1.37 & $2.51^{*}$ \\
\hline Recruitment source & $10.88^{\star * *}$ & & & \\
\hline Shelter & 2.66 & 2.17 & 0.72 & 0.69 \\
\hline Hospital & $12.87^{\star *}$ & $10.70^{* \star *}$ & 1.83 & 1.67 \\
\hline $\begin{array}{l}\text { Intensity of contact } \\
\text { (hours per month) }\end{array}$ & 2.53 & 0.92 & 0.94 & 0.93 \\
\hline $\begin{array}{l}\text { Duration per project } \\
\text { involvement (months) }\end{array}$ & $10.44^{*}$ & $1.22^{\star}$ & 0.94 & 0.80 \\
\hline $\begin{array}{l}\text { Intensity of mainstream } \\
\text { CMH contact (hours pe } \\
\text { month, postintake } \\
\text { months } 5-12 \text { ) }\end{array}$ & 4.09 & 1.00 & $0.99 \dagger$ & 0.99 \\
\hline $\begin{array}{l}\text { Duration mainstream } \\
\text { CMH involve (number } \\
\text { of months, postintake } \\
\text { months } 5-12 \text { ) }\end{array}$ & $7.87^{*}$ & $1.18 \dagger$ & $1.23^{*}$ & $1.31^{* \star}$ \\
\hline
\end{tabular}

of the project, a higher percentage of clients served $(87 \%)$ were placed in independent-type settings than had been reported in other interventions with this population: 67\% for a New York City study (Barrow et al., 1989), 57\% in Ohio (Toomey et al., 1989), and $80 \%$ in Minneapolis (Sosin, Piliavin, \& Westerfelt, 1990).

To link project services with outcomes, the amount of service received and other variables were examined as predictors of follow-up housing status. Multinomial logistic regression was used, with a dependent variable describing four housing outcomes: independent setting, alone; independent setting, with others; supervised dependent setting; and temporary setting (treatment or homeless). All comparisons were with the temporary setting group. Results may be found in Table 4 . 
Four variables were significant predictors of being in a permanent setting (compared with temporary) at 12 months: age group, recruitment source (entered as two dummy variables with $\mathrm{CMH}$ caseload recruitment as the comparative category), duration of involvement with Homeless Project services (in months), and duration of involvement with mainstream $\mathrm{CMH}$ services (during the postintake period of Months 5-12, after most individuals were no longer receiving homeless project services). Overall, the model including these variables was significantly predictive of the data, although it accounted for a modest proportion of the variance (McFadden's $\rho^{2}=.130$ ).

Table 4 lists the effect of each predictor on the odds ratio of each type of permanent setting compared with a temporary (homeless or treatment) setting. Specifically, holding other effects constant, age had a positive effect on the odds that an individual would be in either an independent alone or a supervised dependent setting at 12-month follow-up. Second, compared with individuals recruited from the $\mathrm{CMH}$ caseload, those from inpatient psychiatric hospitals had nearly 11 times the odds of being in an independent setting alone at 12-month follow-up rather than in a temporary setting. This somewhat surprising finding may reflect more chronic functioning problems in those recruited from $\mathrm{CMH}$. As noted earlier, $\mathrm{CMH}$ recruits were disproportionately represented in the Depressed and Substance Abusing clusters. For the hospital recruits, the baseline functioning assessment that was completed during hospitalization may not be reflective of their usual functioning. These outcome differences may also reveal contextual differences in the process of moving into and out of homelessness: loss of housing due to hospitalization may be different on a number of levels from homelessness occurring in the community.

Intensity of service contact (hours of contact per month), either with the Homeless Project or with mainstream $\mathrm{CMH}$ services, showed no significant impact on the odds of any of the permanent setting types compared with a temporary setting at 12-month follow-up. However, duration (in months) of involvement with services, both those provided by the Homeless Project and those of the mainstream CMH agency, had a positive effect on the odds of being in a permanent setting at 12 months.

Conclusions suggesting that the project was a successful contributant to individuals' nonhomeless status at follow-up were bolstered by these results. Duration of project services was a significant predictor of being housed in nonhomeless-type settings, using a multivariate analysis framework. Results also showed that the context variable, recruitment source (i.e., hospitals), was a significant determinant of follow-up housing status. 


\section{DISCUSSION AND APPLICATIONS TO SOCIAL WORK PRACTICE}

\section{Context Effects}

Analyses were summarized from this research demonstration project on homelessness and mental illness to highlight the relationship between context variables studied and variables reflecting client characteristics, service delivery, and client outcomes. Attention to context was admittedly limited and driven by our two-site, multisetting recruitment design. That is, we wanted to include two diverse counties as sites and we wanted to broaden inclusion to encompass the possible major recruitment agencies for persons who are homeless and mentally ill. As responsible evaluators, we determined that these were factors whose effects should be studied. Surprisingly to us, we found that sometimes these context effects statistically overweighed those from other domains.

Thus, as detailed in the Results section, baseline clusters of clients representing homogeneous functioning groups differed significantly according to recruitment sources but related significantly to only one client-level variable external to the clustering variables (diagnosis). The implementation analysis revealed significant county site differences in project implementation activities, with differential success (in terms of numbers recruited and engaged status) in one county for two of the three recruitment sources. Quantitative service analyses showed that recruitment source covaried with the pattern of specific project services received. No client characteristic variables made significant and unique distinctions among service-pattern clusters. The qualitative process analysis found significant differences by county site in intervention strategies reported by staff, although staff perceptions of client-level barriers did not differ by site. Finally, multivariate outcome analyses showed significant effects on follow-up housing status from three variable domains: client characteristics (age), service receipt (duration of project and mainstream CMH services), and context (recruitment source).

Our results parallel those reported by other researchers who have studied the effects of service variables versus client characteristics as predictors of housing outcomes. Service variables have been found to have a prominent impact on housing outcomes, whereas client variables have either a lesser (Blankertz et al., 1992; Rife et al., 1991) or no effect (Morse et al., 1994), or they show fewer significant relationships with outcomes than do service variables (Barrow et al., 1989; Cohen, Onserud, \& Monaco, 1993). The context effect reported by Dixon et al. (1993) that patients referred from the hospital versus the streets have better outcomes, has some similarity to ours, 
except that our comparison of superior outcomes involved hospital versus CMH-referred clients. The Dixon et al. finding could be better understood if their investigation had separately investigated whether these two groups of clients received differential service amounts. The service amount variable was included in our analysis and was found to have a significant and independent effect.

\section{INTERPRETATION}

To persuade other researchers and practitioners of the need to further attend to context effects and their significance, we engage in some speculation as to the mechanisms through which the context variables we analyzed may be operating.

At a client level, different results observed across agencies or sites may merely reflect the client characteristics subsumed by these settings. Setting variables may be more parsimonious representations of demographic and clinical characteristics than are multiple and separate variables obtained from diverse sources such as records or interviews. Other researchers have noted substantial variation in client characteristics by geographical location (Bachrach, 1992; Tessler \& Dennis, 1989). The project sites' different geographic locations also reflected differences in the number and type of settings from which participants could be recruited: for example, homeless shelters for men, women, and families; shelters for individuals with long-term versus acute housing difficulties; and the number and availability of community psychiatric hospital beds. These different settings may reflect client differences that we have not measured; for example, clients with substantial negative experiences with the mental health system may be found more often in certain kinds of shelters (vs. psychiatric hospitals or $\mathrm{CMH}$ ), partly explaining why they are more difficult to serve. The context differences may also reflect the interaction of client characteristics and recruitment setting; for example, individuals having no place to live as a result of a psychiatric hospitalization may have more housing options than someone who has been residing in a shelter for some time.

Site and setting differences may also reflect real differences among agencies in what they can and cannot do and in how they operate. For instance, agency policies or practices concerning whether services are provided in outreach modalities, following nontraditional schedules (i.e., weekends), and so on, will affect the likelihood of enrolling and/or retaining eligible prospective clients, especially in some types of settings. Or, agency employment practices or policies may constrain the ability of the homeless 
service to recruit and hire staff. Who gets hired will also affect the kind, quantity, and quality of services delivered. These constraints on hiring might be the result of agency employment policies regarding full-time versus part-time work or permanent versus temporary work, or preferential hiring for laid-off workers, and so on. They might also reflect market variations in the availability of staff with certain specialty training or experience within a given geographical area.

At a systems level, several mechanisms might be operating to explain the significant context effects. First, historical or current hostilities between the referring agency and the project staff and/or host organization can affect that agency's willingness to refer enough clients or the "right" clients to project services. Significant client subtypes, therefore, might not be represented from certain referral sources or, if included, display "attitude" problems, such as noncompliance. Second, physical restrictions, proximity, logistics, or policies may affect the referring agency's abilities to participate in certain recruitment activities or intervention designs. For example, shelter policies that limit guests' length of stay may reduce the time project staff have to engage prospective clients; or, lack of space for project staff to talk privately with targeted eligible in hospital emergency room settings may impact successful enrollment. Third, characteristics of sites and settings reflect the amount or type of services available to project clients from other sources (e.g., staff or programs at the recruitment agency, existing programs in the community). These resource variations would, therefore, affect how and/or what project services need to be provided by site and setting to stabilize client functioning, obtain and/or maintain housing, and link up with ongoing service systems. As such, setting resource differences should, at minimum, affect the numbers of clients served by a project, if not also the project's success.

\section{CONCLUSION}

Whatever the mechanisms that are operating, context effects appear to have had an important impact on our results. Experientially, context is certainly a dimension acknowledged to be critical to the ecosystems approach to social work practice. Thus, our results suggest that for researchers and practitioners alike, to enhance service provision it is important to address the extent to which any or all of these possible mechanisms are operating through context effects. For both social work practitioners and researchers, this speaks to the need to assess aspects of the organizational and sociocultural environ- 
ments in which services to persons who are homeless are offered and delivered. Such assessments can aid research by improving our predictions of client outcomes by better accounting for sources of variation. Practice can be improved when environmental information can identify in advance what barriers should be addressed: for example, attitudes of staff from recruitment agencies, and resource or policy barriers that may affect a project's ability to hire the most appropriate staff.

The domains outlined by Chen (1990) in his discussion of implementation evaluation provide a helpful framework for conceptualizing what type of information should be collected:

1. Characteristics of staff delivering the intervention: especially their training and expertise and their attitudes toward serving the target population and the services they are required to deliver. To note here are limitations posed by hiring requirements of the implementing agency as well as that presented by the human resource pool in terms of qualifications, training type and amount, service philosophy, and so on.

2. Service activities of the project: Amount and type of services should be continually monitored against expectations and to determine how service provision may change over time. Use of service categories from the current research could be a starting place. Measures of service quality and of client satisfaction should be additional dimensions.

3. Microcontext: Characteristics of the host agency should be identified, namely, What services relevant to the target group does it provide? Where is the project housed organizationally? What are the implications for visibility and impact? What is the relationship between the project and relevant agency programs? Where likely problems are observed in advance, administrative shifts are warranted.

4. Macrocontext: concerns the potential and actual recruitment sources for the project. On an ongoing basis, for each source, programs should monitor the numbers and types of clients referred compared to the characteristics of other clients. Other significant aspects of the microcontext to be assessed include relationships between the project and the recruitment agency; resources and relevant program availability for target clients; community resources available for housing, income supports, social services, employment.

We should note that for research purposes, data collection in many of these domains can be severely affected by methodological limitations. Thus, for example, well-developed methods to categorize services or to collect data on their amounts or intensity do not exist. Progress may be quite slow in understanding context, given poor quality data input, unless researchers themselves or external funding sources are willing to invest time and money 
in measurement development. Combined interest from practitioners and researchers for better assessment of context, using quantitative and qualitative approaches, could move the knowledge base ahead more rapidly.

To further explore the significance of context and endorse the critical multiplism perspective proposed by Shadish (1993), we recommend that future development of innovative programs use diverse sites and recruitment sources, to the extent possible. Shadish notes, "We can never totally trust the results of a single study" (p. 33). He recommends multiple sites and multiple studies. However, he cautions against "mindless multiplism" (p. 23)introducing variation for the mere sake of doing so-and he notes that there is "little careful thought about how one could best sample options." (p. 30) Thus, sites and recruitment sources should optimally be preselected following a strategy to investigate and learn systematically about factors that are thought to affect operations or outcomes: for example, shelters serving different types of clients, with differing operating philosophies, differing levels of resources, and differing receptivity to mental health collaboration. This approach has benefits to social work practice and administration. This means, of course, that the basic building block is to formulate good intervention questions, which have emerged from comprehensive needs and resource assessments, and from getting to know the client and the systems in which he or she is embedded. These are major tenets of good social work practice; they should be followed for good social work research as well.

\section{REFERENCES}

Argeriou, M., \& McCarty, D. (1993). The use of shelters as substance abuse stabilization sites. Journal of Mental Health, 20, 126-137.

Bachrach, L. L. (1992). What we know about homelessness among mentally ill persons: An analytical review and commentary. Hospital and Community Psychiatry, 43, 453-464.

Barrow, S. M., Hellman, F., Lovell, A. M., Plapinger, J., \& Streuning, E. L. (1989). Effectiveness of programs for the mentally ill homeless. New York: Psychiatric Institute.

Barrow, S. M., Hellman, F., Lovell, A. M., Plapinger, J. D., \& Streuning, E. L. (1989/1991). Evaluating outreach services: Lessons from a study of five programs. In N. L. Cohen (Ed.), Psychiatric outreach to the mentally ill, new directions for mental health services (Vol. 52, pp. 29-46). San Francisco: Jossey-Bass.

Belcher, J. R. (1991). Moving into homelessness after psychiatric hospitalization. Journal of Social Service Research, 14, 63-77.

Bennett, M. I., Gudeman, J. E., Jenkins, L., Brown, A., \& Bennett, M. B. (1988). The value of hospital-based treatment for the homeless mentally ill. American Joumal of Psychiatry, 145 , 1273-1276. 
Blankertz, L. E., \& Cnaan, R. A. (1992). Principles of care for dually diagnosed homeless persons: Findings from a demonstration project. Research on Social Work Practice, 2, 448-464.

Blankertz, L. E., \& Cnaan, R. A. (1994). Assessing the impact of two residential programs for dually diagnosed homeless individuals. Social Service Review, 68, 536-560.

Blankertz, L. E., Cnaan, R. A., \& Saunders, M. (1992). Assessing the impact of serving the long-term mentally disabled homeless. Journal of Sociology and Social Welfare, 19, 199220.

Blankertz, L. E., Cnaan, R. A., White, K., Fox, J., \& Messinger, K. (1990). Outreach efforts with dually diagnosed homeless persons. Families in Society, 71, 387-395.

Bybee, D., Mowbray, C. T., \& Cohen, E. (1994). Short versus longer term effectiveness of an outreach program for the homeless mentally ill. American Joumal of Community Psychology, 22, 181-210.

Bybee, D., Mowbray, C. T., \& Cohen E. (1995). Evaluation of a homeless mentally ill outreach program: Differential short-term effects. Evaluation and Program Planning, 18, 13-24.

Carling, P. J. (1992). Homes or group homes? Future approaches to housing, support and integration for people with psychiatric disabilities. Adult Residential Care Joumal, 6, 87-96.

Caton, C.L.M., Wyatt, R. J., Grunberg, J., \& Felix, A. (1990). An evaluation of a mental health program for homeless men. American Journal of Psychiatry, 147, 286-289.

Chen, H. (1990). Theory-driven evaluations. Newbury Park, CA: Sage.

Cohen, C., Onserud, H., \& Monaco, C. (1993). Outcomes for the mentally ill in a program for older homeless persons. Hospital and Community Psychiatry, 44, 650-656.

Cohen, E. H., Mowbray, C. T., Bybee, D., Yeich, S., Ribisl, K., \& Freddolino, P. P. (1993). Tracking and follow-up methods for research on homelessness. Evaluation Review, I7, 333-354.

Cohen, N. L., \& Marcos, L. R. (1992). Outreach intervention models for the homeless mentally ill. In H. R. Lamb, L. L. Bachrach, \& F. I. Kass (Eds.), Treating the homeless mentally ill (pp. 141-158). Washington, DC: American Psychiatric Press.

Dennis, D. L., Buckner, J. C., Lipton, F. R., \& Levine, I. S. (1991). A decade of research and services for homeless mentally ill persons: Where do we stand? American Psychologist, 46, 1129-1138.

Dixon, L., Friedman, N., \& Lehman, A. (1993). Housing patterns of homeless mentally ill persons receiving assertive treatment services. Hospital and Community Psychiatry, 44, 286-289.

First, R. J., Rife, J. C., \& Kraus, S. (1990). Case management with people who are homeless and mentally ill: Preliminary findings from an NIMH demonstration project. Psychosocial Rehabilitation Journal, 14, 87-91.

Fischer, P. J. (1989). Estimating the prevalence of alcohol, drug and mental health problems in the contemporary homeless population: A review of the literature. Contemporary Drug Problems, 16, 333-390.

Fischer, P., Drake, R. E., \& Breakey, W. R. (1992). Mental health problems among homeless persons: A review of epidemiological research from 1980 to 1990 . In H. R. Lamb, L. L. Bachrach, \& F. I. Kass (Eds.), Treating the homeless mentally ill (pp. 75-94). Washington, DC: American Psychiatric Press.

Hagen, J. L. (1987). Gender and homelessness. Social Work, 32, 312-316.

Hazel, K., Herman, S. E., \& Mowbray, C. T. (1991). Characteristics of adults with serious mental illness in a public mental health system. Hospital and Community Psychiatry, 42, 518-525. 
Hoff, M. D., Briar, K. H., Knighton, K., \& Van Ry, A. (1992). To survive and to thrive: Integrating services for the homeless mentally ill. Journal of Sociology and Social Welfare, 19, 235-252.

Johnson, A. K. (1989). Measurement and methodology: Problems and issues in research on homelessness. Social Work Research and Abstracts, 25, 12-26.

Johnson, A. K., \& Cnaan, R. A. (1995). Social work practice with homeless persons. Research on Social Work Practice, 5, 340-382.

Kiesler, C. A. (1991). Homelessness and public policy priorities. American Psychologist, 46, 1245-1252.

Leda, C., \& Rosenheck, R. (1992). Mental health status and community adjustment after treatment in a residential treatment program for homeless veterans. American Joumal of Psychiatry, 149, 1219-1224.

Lipton, F. R., Nutt, S., \& Sabatini, A. (1988). Housing the homeless mentally ill: A longitudinal study of a treatment approach. Hospital and Community Psychiatry, 39, 40-45.

Marcos, L. R., Cohen, N. L., Nardacci, D., \& Brittain, J. (1990). Psychiatry takes to the streets: The New York city initiative for the homeless mentally ill. American Journal of Psychiatry, 147, 1557-1561.

Morse, G. A., Calsyn, R. J., \& Allen, G. (1994). Helping homeless mentally ill people: What variables mediate and moderate program effects? American Journal of Community Psychology, 22, 661-683.

Morse, G. A., Calsyn, R. J., Allen, G., Tempelhoff, B., \& Smith, R. (1992). Experimental comparison of the effects of three treatment programs for homeless mentally ill people. Hospital and Community Psychiatry, 43, $1005-1009$.

Mowbray, C. T., \& Bybee, D. (1996). Services provided by a homeless intervention: Policy and planning implications, Journal of Sociology and Social Welfare, XXIII(4), 129-146.

Mowbray, C. T., Bybee, D., \& Cohen, E. (1993). Describing the homeless mentally ill: Cluster analysis results. American Journal of Community Psychology, 21, 67-93.

Mowbray, C. T., Cohen, E., \& Bybee, D. (1991). Services to individuals who are homeless and mentally ill: Implementation evaluation. In D. Rog (Ed.), Evaluating programs for the homeless, new directions for program evaluation, (Vol. 52, pp. 75-90). San Francisco: Jossey-Bass.

Mowbray, C. T., Cohen, E., \& Bybee, D. (1993). The challenge of outcome evaluation in homeless services: Engagement as an intermediate outcome measure. Evaluation and Program Planning, 16, 337-346.

Mowbray, C. T., Cohen, E., Harris, S. N., Trosch, S., Johnson, S., \& Duncan, B. (1992). Serving the homeless mentally ill: Mental health linkage. Journal of Community Psychology, 20, 215-227.

Mowbray, C. T., Thrasher, S., Cohen, E., \& Bybee, D. (1996). Improving social work practice with persons who are homeless and mentally ill. Joumal of Sociology and Social Welfare, XXIII(4), 3-24.

Ribisl, K. M., Walton, M. A., Mowbray, C. T., Luke, D. A., Davidson, W. S., \& BootsMiller, B. J. (1996). Minimizing participant attrition in panel studies through the use of effective retention and tracking strategies: Review and recommendations. Evaluation and Program Planning, $19(1), 1-25$.

Rife, J. C., First, R. J., Greenlee, R. W., Miller, L. D., \& Feichter, M. A. (1991). Case management with homeless mentally ill people. Health and Social Work, 16, 58-67.

Shadish, W. R. (1993). Critical multiplism: A research strategy and its attendant tactics. New directions for program evaluation (Vol. 60, pp. 13-57). San Francisco: Jossey-Bass.

Sheridan, M. J., Gowen, N., \& Halpin, S. (1993). Developing a practice model for the homeless mentally ill. Families in Society, 74, 410-421. 
Solomon, P., \& Draine, J. (1995). Jail recidivism in a forensic case management program. Health and Social Work, 20, 167-173.

Sosin, M., Pilavin, I., \& Westerfelt, H. (1990). Toward a longitudinal analysis of homelessness. Journal of Social Issues, 46(4), 107-174.

Stoner, M. (1989). Money management services for the homeless mentally ill. Hospital and Community Psychiatry, 40, 751-753.

Susser, E., Goldfinger, S. M., \& White, A. (1990). Some clinical approaches to the homeless mentally ill. Community Mental Health Journal, 26, 463-480.

Susser, E. S., Lin, S. P., \& Conover, S. A. (1991). Risk factors for homelessness among patients admitted to a state mental hospital. American Journal of Psychiatry, 148, 1659-1664.

Tessler, R. C., \& Dennis, D. L. (1989). A synthesis of NIMH-funded research concerning persons who are homeless and mentally ill. Rockville, MD: National Institute of Mental Health.

Toomey, B. G., First, R. J., Rife, J. C., \& Belcher, J. R. (1989, December). Evaluating community care for homeless mentally ill people. Social Work Research and Abstracts, 21-26. 